F. Van den Bosch Consultant for: AbbVie, Celgene Corporation, Merck, Pfizer, UCB, Janssen, E. Lespessailles Grant/research support from: Amgen, Eli Lilly, Novartis, Servier, Speakers bureau: Amgen, Eli Lilly, Novartis, Servier, M. Mcllraith Employee of: Celgene Corporation, D. Nguyen Employee of: Celgene Corporation, L. Teng Employee of: Celgene Corporation, C. Edwards Grant/research support from: Celgene Corporation, Pfizer, Roche, Samsung, Consultant for: Celgene Corporation, Pfizer, Roche, Samsung, Speakers bureau: Abbott, GSK, Pfizer, Roche

DOI: 10.1136/annrheumdis-2017-eular.3019

\section{FRI0514 PSORIATIC ARTHRITIS IS ASSOCIATED WITH DIAGNOSTIC DELAY AND WORSE OUTCOME AT THREE MONTHS WHEN COMPARED TO RHEUMATOID ARTHRITIS: RESULTS FROM THE UK NATIONAL AUDIT FOR INFLAMMATORY ARTHRITIS}

R. Holland ${ }^{1}$, A. Davis ${ }^{2}$, A. Green ${ }^{2}$, A. Nightingale ${ }^{2}$, R. Charlton ${ }^{2}$, E. Cullen ${ }^{3}$ N. McHugh ${ }^{1}$. 'Royal National Hospital for Rheumatic Diseases; ${ }^{2}$ University of Bath, Bath; ${ }^{3}$ Celgene Ltd, London, United Kingdom

Background: Psoriatic arthritis (PsA) is underdiagnosed in primary care, and can be difficult to distinguish from osteoarthritis. Accumulating evidence suggests that diagnostic delay is associated with poorer functional outcome despite treatment. Objectives: To develop a better understanding of the diagnostic delay and burden of disease in patients with PsA, and to investigate management within the first three months of diagnosis.

Methods: Data were analysed on all participants with a final diagnosis of PsA from The National Clinical Audit for Rheumatoid and Early Inflammatory Arthritis, undertaken by the British Society for Rheumatology and commissioned by the Healthcare Quality Improvement Programme, recruited between 1/2/2014 and 30/10/2015. Data were collected from patients and clinicians at baseline and three months. 1016 participants with PsA (mean age $49.4 \pm 14.5$ years; $54 \%$ female) were matched $1: 1$ by age and sex with participants with Rheumatoid Arthritis (RA).

Results: Patients with PsA had a significantly longer delay to presentation and diagnosis than those with RA $(p<0.02$, Table 1$)$, and this remained significant when adjusted for age, sex, ethnicity and social status.

PsA patients had lower median tender (4.0 vs 7.0 ) and swollen (3.0 vs 5.0 ) joint counts and lower mean baseline ESR (21.9 vs $27.8 \mathrm{~mm} / \mathrm{hr}$ ) and CRP (16.2 vs $24.2 \mathrm{mg} / \mathrm{L})$ values than patients with $R A$ ( $p<0.01$ for all comparisons), and this remained significant when adjusted for potential confounders. Mean baseline scores for the Inflammatory Arthritis Impact of Disease (IAID) questionnaire were lower in patients with PsA $(5.34 \pm 2.25$ vs $5.94 \pm 2.35$ in RA, lower scores indicating less impact), although this was not statistically significant when adjusted for demographics and disease activity $(p=0.36)$. There was no significant difference between physical function at baseline between the groups (median HAQ 0.88 PsA vs $1.13 \mathrm{RA}, \mathrm{p}=0.70)$.

At follow-up, patients with PsA had significantly higher mean IAID scores $(4.32 \pm 2.60$ vs $3.78 \pm 2.56, P<0.05)$. In those with paired results, the mean improvement in IAID score was $1.32(95 \% \mathrm{Cl} 0.99-1.65)$ in PsA vs $2.37(95 \% \mathrm{Cl}$ 2.07-2.67) in RA. In patients with high disease activity at baseline (DAS28 > 5.1) a good EULAR response was seen in only $21.4 \%$ in PsA vs $30.3 \%$ in RA. There was a marked difference in the DMARDs initially prescribed, and the differences

Table 1. Median delay in weeks

\begin{tabular}{lccccc}
\hline & \multicolumn{2}{c}{ PsA } & & \multicolumn{2}{c}{ RA } \\
\cline { 2 - 3 } \cline { 5 - 6 } & Unadjusted & Adjusted $^{\star}$ & & Unadjusted & Adjusted $^{*}$ \\
\hline Symptoms to GP Presentation & 8.9 & 8.9 & & 7.1 & 6.6 \\
GP Presentation to Referral & 5.3 & 5.4 & & 4.3 & 4 \\
GP Presentation to Diagnosis & 12.4 & 12.1 & & 9.9 & 9.7 \\
Symptoms to Diagnosis & 29.0 & 28.6 & & 21.4 & 21.6 \\
\hline
\end{tabular}

${ }^{*}$ Adjusted for age, sex, ethnicity and deprivation Index; $p<0.02$ for all between group comparisons.
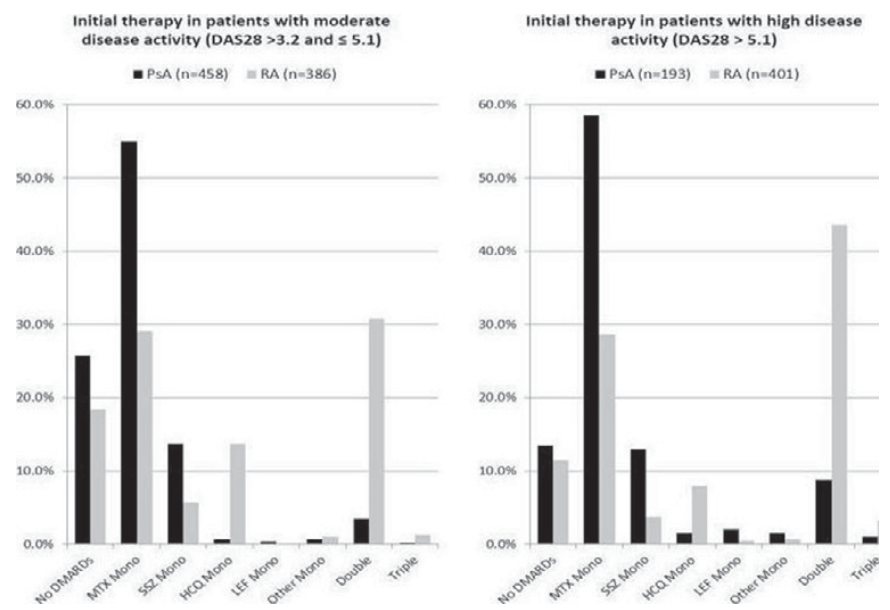

remained significant when only those with a DAS28 score indicating moderate or high disease activity at presentation were analysed, as shown in Figure 1.

Conclusions: This study demonstrates that patients with PsA have a longer delay to diagnosis between both symptom onset and presentation to primary care, and referral to secondary care and diagnosis than those with RA. Despite similar disease impact and physical function at diagnosis, patients with PsA are less likely to receive combination DMARD treatment, and have increased disease burden at three months.

Disclosure of Interest: None declared

DOI: 10.1136/annrheumdis-2017-eular.5066

\section{FRI0515 CLASSIC CARDIOVASCULAR RISK FACTORS AND MINIMAL DISEASE ACTIVITY IN PSORIATIC ARTHRITIS: RESULTS OF A SPANISH MULTICENTER STUDY}

$\underline{\text { R. Queiro }}^{1}$, J.D. Cañete ${ }^{2}$, C. Montilla ${ }^{3}$, M.A. Abad $^{3}$, M. Montoro ${ }^{3}$, S. Gómez $^{3}$, A. Cábez $^{3}$, J.C. Torre Alonso ${ }^{3}$, J.A. Román Ivorra ${ }^{3}$, J. Sanz $^{3}$, J. Salvatierra $^{3}$, J. Calvo Alén ${ }^{3}$, A. Sellas ${ }^{3}$, F.J. Rodriguez ${ }^{3}$, A. Bermúdez $^{3}$, M. Romero $^{3}$, M. Riesco ${ }^{3}$, J.C. Cobeta $^{3}$, F. Medina ${ }^{3}$, A. Aragón ${ }^{3}$, M.L. García ${ }^{3}$

A. Urruticoechea ${ }^{3} .{ }^{1}$ Rheumatology, Hospital Universitario Central de Asturias, Oviedo; ${ }^{2}$ Rheumatology, HU, Clinic and IDIBAPS, Barcelona, Spain; ${ }^{3}$ Affiliation not provided

Background: Some cardiovascular risk factors (CVRF) have been related to poorer responses to biological therapy ${ }^{1}$. We aimed to evaluate the potential link between the MDA response and the presence of CVRF in patients treated with traditional and/or biological DMARDs.

Objectives: The objective has been to evaluate the potential association between classic CVRF and the probability of reaching an MDA response in PsA patients.

Methods: Cross-sectional study carried out at 25 rheumatology outpatient clinics in patients who fulfilled the Classification for Psoriatic Arthritis (CASPAR) criteria with at least one year disease duration, and treated with biological or conventional synthetic (cs) DMARDs according to routine clinical practice in Spain. Patients were considered in MDA if they met at least $5 / 7$ of the MDA criteria ${ }^{2}$. The relationship between MDA and CVRF was evaluated by uni and multivariate analyses.

Results: 227 patients were included, 133 (58.6\%) were in MDA state (52\% on anti-TNF $\alpha$ monotherapy, $24 \%$ on csDMARD monotherapy, $24 \%$ on anti-TNF $\alpha$ in combination with csDMARD). Among the classic CVRF, tobacco (crude OR: 0.54), sedentary lifestyle (crude OR: 1.95), hyperuricemia (crude OR: 2.01) and obesity (crude OR: 1.54) were related to the likelihood of MDA in the univariate model $(p<0.25)$. The only CVRF related to the MDA response in the multivariate analysis was a sedentary lifestyle (OR $3.13,95 \% \mathrm{Cl}: 1.50-6.53 ; \mathrm{p}=0.002$ ). We did not find any association between the number of CVRF and the MDA response.

Conclusions: Contrary to what has been found in other studies, in this crosssectional multicenter study we could not find any relationship between traditional CVRF (except for sedentary lifestyle) and MDA. In any case, patients with psoriatic disease should be encouraged to maintain healthy lifestyle habits.

References:

[1] Ogdie A, Eder L. Improving cardiovascular health and metabolic comorbidities in patients with psoriatic arthritis. Int J Clin Rheumatol 2015; 10(6):451-459.

[2] Coates LC, Fransen J, Helliwell PS. Defining minimal disease activity in psoriatic arthritis: a proposed objective target for treatment. Ann Rheum Dis 2010; 69(1):48-53.

Acknowledgements: This study was funded by Pfizer.

Disclosure of Interest: None declared

DOI: 10.1136/annrheumdis-2017-eular.4083

\section{FRI0516 ASSESSMENT OF DISEASE REMISSION BY POWER DOPPLER ULTRASONOGRAPHY IN PATIENTS WITH PSORIATIC ARTHRITIS}

S. Monov ${ }^{1}$, R. Shumnalieva ${ }^{1}$, D. Monova ${ }^{2}$, A. Kopchev ${ }^{1} .{ }^{1}$ Department of Internal Medicine, Clinic of rheumatology, Medical University - Sofia; ${ }^{2}$ Medical Institute-MVR, Medical University-Sofia, Sofia, Bulgaria

Background: Treatment strategies nowadays are targeting clinical remission or low disease activity. In some patients with psoriatic arthritis (PsA) clinical findings defer from the ultrasonographic evidence of inflammation which raise the need for revising the remission criteria in the clinical practice.

Objectives: The aim of our study was to estimate the presence of subclinical synovitis by power Doppler ultrasonography (PDUS) in PSA patients, who were considered as being in clinical remission defined by DAS28-ESR (Disease activity score of 28 joints - erythrocyte sedimentation rate) for at least 6 months during the treatment course.

Methods: 64 PsA patients in clinical remission based on DAS28 - ESR $<2.6$ were included in the study. The patients were examined by two independent rheumatologists. The affected joints were assessed by PDUS (MyLab 60, Esaote) for the presence of synovial hypertrophy $(\mathrm{SH})$ and synovitis scored from 0 to 3 based on the presence and intensity of PD signal. Disease activity was determined by the presence of $\mathrm{SH} \geq 2$ degree and a positive PD signal.

Results: We found a persistent synovitis in 23 (35.9\%) of the PsA with clinical remission of the peripheral joint involvement. Active synovitis was also found in 7 
(10.9\%) of the patients with DAS28 $<2.6$ which were on systemic corticosteroid (CS) treatment regimen.

Conclusions: The presence of active synovitis on PDUS in a significant part of the studied PsA patients (35.9\%) which were considered as being in clinical remission for at least 6 months showed that these kind of patients need to be closely followed-up and adequately treated. The systemic CS treatment does not exclude the presence of disease activity in PsA. Further studies for assessment of the synovitis will establish correct criteria for defining and monitoring the disease activity in PsA.

Disclosure of Interest: None declared

DOI: 10.1136/annrheumdis-2017-eular.6634

\section{FRI0517 QUALITY OF LIFE IN PATIENTS WITH EARLY PSORIATIC ARTHRITIS}

S. Monov, A. Kopchev. Clinic of Rheumatology, Department of Internal Medicine, Medical University, Sofia, Sofia, Bulgaria

Background: Psoriatic arthritis (PsA) is a chronic systemic inflammatory disease. Affecting skin, joints, entheses and dactylitis, its impact on health-related qualityof-life (HRQoL) could be substantial.

Objectives: The aim of this study was to describe HRQoL in newly diagnosed PsA patients taking into account skin involvement, swollen joints, tender enthuses and dactylitis.

Methods: HRQoL was assessed by 8 subscales of the Short-Form 36 (SF-36) questionnaire $(0-100$, higher score represents a better HRQoL). Patients were classified in arthritis subtypes (i.e. mono-, oligo- or polyarthritis) by rheumatologist. Entheses were evaluated using the Leeds Enthesitis Index (LEI) and Maastricht Ankylosing Spondylitis Enthesitis Score (MASES; positive if tender entheses $>1$ ). Psoriasis was evaluated using the Psoriasis Area Severity Index (PASI; mild: 0-7; moderate/severe: $>7$ ) and dactylitis using the Leeds Dactylitis Index (LDI).

Results: 87 patients (48 male, 39 female, mean age 47,6 $\pm 15,3$ ) with PsA (21 had monoarthritis, 49 - oligoarthrit and 17 - polyarthritis) completed the SF-36 were included in the study. Psoriasis was mild in $63(72,41 \%)$ patients and moderate/severe in $12(13,79 \%)$ patiients. At least one digit with dactylitis was present in $10(11,49 \%)$ of the patients. A tender enthesis was present in 39 $(44,83 \%)$ of patients. Mean scores of the subdomains in the SF-36 were similar across the different arthritis groups, with slightly worse scores for polyarthritis compared to mono- and oligoarthritis. However, when stratifying these groups for the presence of a tender enthesis, HRQoL decreased substantially for all groups across all subdomains of the SF-36, with a median difference of 12,9 points. Irrespective of joint involvement, a tender enthesis decreased the mean scores of all subdomains significantly compared to the non-tender enthesis group $(p<0,05)$. Severity of psoriasis and presence of dactylitis did not lead to significantly different SF-36 values compared to those not affected.

Conclusions: Having tender entheses impacts HRQoL severly in both its physical and mental dimensions in incident untreated PsA.

Disclosure of Interest: None declared

DOI: 10.1136/annrheumdis-2017-eular.6603

\section{FRI0518 PRESCRIPTION PATTERNS OF TUMOUR NECROSIS FACTOR INHIBITOR AND USTEKINUMAB IN PSORIATIC ARTHRITIS: A NORDIC POPULATION-BASED COHORT STUDY}

T.S. Jørgensen ${ }^{1}$, L. Dreyer ${ }^{1}$, B. Guőbjörnsson ${ }^{2}$, M.L. Hetland ${ }^{1}$, B. Glintborg ${ }^{1}$ J. Askling ${ }^{3}, K$. Chatzidionysiou ${ }^{3}$, D. Di Giuseppe ${ }^{3}$, L. Jacobsson ${ }^{3}$,

J.K. Wallman ${ }^{3}$, E.K. Kristianslund ${ }^{4}$, I.C. Olsen ${ }^{4}$, K. Fagerli ${ }^{4}$, E. Lie $^{4}$

D. Nordström ${ }^{5}$, K. Aaltonen ${ }^{5}$, J. Joensuu ${ }^{5}$, T.J. Love ${ }^{2}$, A.J. Geirsson ${ }^{2}$,

L.E. Kristensen ${ }^{1} .{ }^{1}$ On behalf of the DANBIO registry, Copenhagen, Denmark;

${ }^{2}$ On behalf of the ICEBIO registry, Reykjavik, Iceland; ${ }^{3}$ On behalf of the $S R Q$ registry, Stockholm, Sweden; ${ }^{4}$ On behalf of the NOR-DMARD registry, Oslo, Norway; ${ }^{5}$ On behalf of the ROB-FIN registry, Helsinki, Finland

Background: Psoriatic arthritis (PsA) is a chronic inflammatory disorder associated with skin and joint manifestations, several extra-articular symptoms, various comorbidities, and disability. The emergence of tumour necrosis factor inhibitor (TNFi) therapy has dramatically changed the course of disease. Over the past decade new TNFi therapies have emerged (certolizumab pegol and golimumab), and recently ustekinumab and secukinumab have also become available for PsA. Objectives: The objective of this study was to assess the relative use of biological agents (bDMARDs) in PsA from 2006 through 2014, using data from the Nordic Rheumatology registers.

Methods: Based on data from the observational registers DANBIO, ICEBIO, NOR-DMARD, ROB-FIN, and SRQ registers, PsA patients initiating treatment with bDMARDs as a first or subsequent biological therapy were identified. Adalimumab, etanercept and infliximab were grouped as "first generation TNFi therapies"; certolizumab pegol and golimumab were grouped as "second generation TNFi", Treatments with ustekinumab during the study period were also identified. Descriptive statistics for prescription patterns of bDMARD therapy were calculated.

Results: A total of 11,458 treatment initiations were identified (DANBIO 3,068, ICEBIO 357, NOR-DMARD 1,113, ROB-FIN 708, SRQ 6,212). 54\% of the patients were female. Overall, 5,695 patients initiated a first generation TNFi, 912 a second generation $\mathrm{TNFi}$, and 16 ustekinumab, as their first course of biological treatment. The corresponding numbers for those initiating a second (or more) biological treatment were 3,606, 1,090 and 139 patients, respectively. The figure displays the annual number of treatment initiations stratified by treatment type. The total yearly number of first course biological treatment increased significantly throughout the period $(p<0.001)$, and this was also the case for patients switching therapy $(p<0.001)$, indicating a previously unmet need for biological therapies in the Nordic population. The annual number of patients initiating first generation TNFi both as first and subsequent course of therapy decreased significantly towards the end of the study period $(p<0.001)$. This drop was more than offset by a rapid increase in initiation of second generation TNFi treatments $(p<0.001)$. Ustekinumab was primarily used as second or subsequent course of therapy in PsA. The same pattern was seen when stratified for country (data not shown).

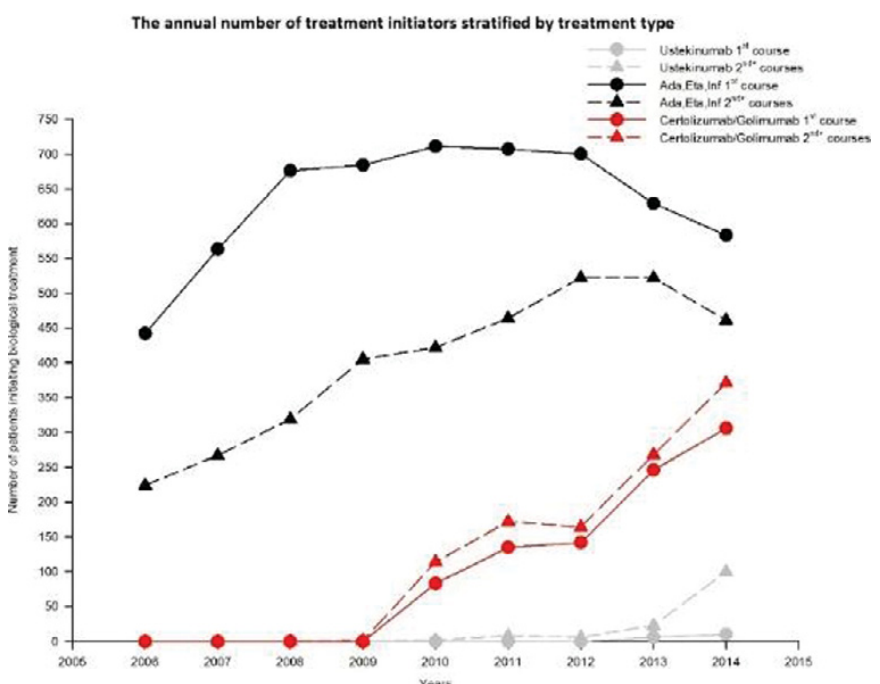

Conclusions: Across the Nordic countries the prescription pattern for biological therapies for PsA has changed significantly over time. After 2012 initiation of the first generation TNFi is decreasing both as first and second course therapy, whereas second generation TNFi are increasing both as first and second course of biologic intervention. Collaboration across registers will allow for robust assessment of the uptake of newer biological therapies.

Acknowledgements: This study was partly funded by a grant from NordForsk and Janssen Pharmaceuticals.

Disclosure of Interest: T. S. Jørgensen Speakers bureau: Abbvie, Roche, Novartis, UCB, Biogen, L. Dreyer Speakers bureau: MSD, UCB and Janssen Pharmaceuticals, B. Guőbjörnsson Speakers bureau: Actavis, Celgene, MSD, Pfizer, M. Hetland Speakers bureau: BMS, MSD, AbbVie, Roche, Eli Lilly, Pfizer, Orion, Novartis, B. Glintborg Speakers bureau: Abbvie, J. Askling Grant/research support from: AstraZeneca, UCB, Lilly, Pfizer, Roche, Merck,Samsung, Janssen, K. Chatzidionysiou Speakers bureau: AbbVie, Pfizer, Eli Lilly, UCB, Roche., D. Di Giuseppe: None declared, L. Jacobsson Consultant for: Abbvie, Celegen, MSD, Novartis and UCB, J. Wallman Consultant for: Novartis, Celgene, UCB, E. Kristianslund: None declared, I. Olsen: None declared, K. Fagerli: None declared, E. Lie Speakers bureau: AbbVie, Celgene, Hospira and Pfizer., D. Nordström Speakers bureau: AbbVie, BMS, Lilly, MSD, Novartis, Pfizer, Roche, UCB., K. Aaltonen: None declared, J. Joensuu Speakers bureau: Pfizer., T. J. Love: None declared, A. J. Geirsson: None declared, L. E. Kristensen Speakers bureau: Pfizer, AbbVie, Amgen, UCB, Celgene, BMS, MSD,

DOI: 10.1136/annrheumdis-2017-eular.4690

\section{FRI0519 EFFECT OF BIOLOGICS ON FATIGUE IN PSORIATIC ARTHRITIS: A SYSTEMATIC LITERATURE REVIEW WITH META-ANALYSIS}

T. Reygaerts ${ }^{1,2}$, S. Mitrovic ${ }^{1}$, B. Fautrel ${ }^{1}$, L. Gossec ${ }^{1} .{ }^{1}$ Service de Rhumatologie, Pitie-Salpétrière Hospital, Paris, France; ${ }^{2}$ Service de Rhumatologie et de Médecine Physique, Erasme Hospital, Bruxelles, Belgium

Background: Fatigue is an important aspect of disease both in rheumatoid arthritis (RA) and in psoriatic arthritis (PsA) and is of high priority for patients. In RA, a recent Cochrane meta-analysis found a small effect of biologics on fatigue (standardized mean difference, SMD, 0.43; $95 \%$ confidence interval, $\mathrm{Cl}$ : 0.38-0.49).(1) Little is known about this effect in PsA.

Objectives: To assess the effect of biologics on fatigue in PsA randomised controlled trials (RCTs) and to compare this effect with the effect in the same trials, on pain, through a systematic literature review (SLR) and meta-analysis (MA).

Methods: SLR up to January 2017 in PubMed, Embase and Cochrane trials database and in recent congress abstracts, using key words related to PsA and biologics. All RCTs in PsA of any biologic therapy, assessing fatigue (whatever the 